\title{
Genetics of local adaptation in salmonid fishes
}

\section{Heredity (2011) 106, 401-403; doi:10.1038/hdy.2010.158}

Local adaptation, whereby individuals of a local population exhibit higher fitness in their local environment compared with individuals from a different population and environment (Kawecki and Ebert, 2004), has been suggested to be especially common in fishes of the family Salmonidae (Taylor, 1991). This is because of several factors, not least of which is their renowned accurate homing ability, which results in a high level of population structuring. However, hard evidence supporting the local adaptation paradigm in salmonids is, actually, still lacking in most cases (Adkison, 1995; Garcia de Leaniz et al., 2007). This is not surprising, given the challenging nature of the multi-disciplinary longterm approaches generally required to provide evidence of local adaptation 'beyond reasonable doubt' (Adkison, 1995; Kawecki and Ebert, 2004). Although a number of characteristics in fact make salmonid fishes quite impractical for conducting research on local adaptation (generation times of 2-7 years, large body size and anadromy), the advantages, in part because of their commercial importance, outweigh the disadvantages (Stearns and Hendry, 2004). For example, long-term data series, including census sizes and phenotypic data, have been collected for numerous salmonid populations (for example, McGinnity et al., 2009). Often, scale or otholith samples have also been taken and, although originally archived for assessment of age and growth rates, they have subsequently become a valuable source of DNA (Nielsen and Hansen, 2008). Further, extensive hatchery facilities are available, thus enabling common garden experiments to be conducted (for example, Jensen et al., 2008). An additional side effect of their appreciation as an angling target is that salmonid fishes have been frequently stocked in non-native habitats. As the exact time of transfers is often known, such systems provide unique opportunities to assess the rate and mechanisms of adaptation to novel environments.

This special issue includes two reviews and six primary articles, each of which capitalise on one or more of the advantages noted above in order to study the genetics of local adaptation using a variety of approaches, differing geographical and temporal scales and in several salmonid species. It commences with a review by Fraser et al. (2011), who aim to answer questions such as: what is the extent and scale of local adaptation in salmonids, how quickly does it arise, and what is its underlying molecular basis? They find that local adaptation is evident at a variety of spatial scales, from just a few $\mathrm{km}$ to $>1000 \mathrm{~km}$, and can evolve quickly (6-30 generations). Using a meta-analysis, they estimate the frequency of studies in which the local adaptation hypothesis is supported to be $\approx 55-70 \%$, with local populations having 1.2 times the average fitness advantage. They also note that local adaptation is generally more frequent and stronger as the geographic scale between populations being compared increases. In summarising the phenotypic/molecular approaches that have been used to detect natural selection in salmonids, they conclude that there are still no studies in salmonids that have established a causal link between molecular variation and variation in fitness, and highlight the need for integrative approaches and hence greater collaboration between disciplines to fill this knowledge gap in the future.

The second review by Hutchings (2011) complements the first by summarising earlier work studying genetic variation in phenotypic plasticity in salmonid fishes. More specifically, it provides a historical background and conducts an exhaustive literature review of research on genetic variability in continuous and discontinuous (threshold) reaction norms. It concludes that there is compelling evidence that plasticity is heritable and that population differences in reaction norms can reflect adaptive responses, by natural selection, to local environments. A list of 20 topics for future research in the field is also provided. These reviews are followed by a study by Carlson et al. (2011), who utilise long-term data sets on sockeye salmon (Oncorhynchus nerka) as an example for demonstrating how an eco-evolutionary framework can be used to understand the consequences of ongoing evolutionary change for populations, communities and ecosystems. More specifically, they outline the consequences that natural selection on body size can have for salmon population dynamics, community (bear-salmon) interactions and ecosystem processes (fluxes of salmon biomass between habitats), as well as how local adaptation might influence eco-evolutionary dynamics.

The study by Kinnison et al. (2011) is one of two studies in the special issue that exploit salmonid populations stocked in non-native regions. They study the genetic basis of phenotypic divergence in size at age and age at maturity in Chinook salmon (Oncorhynchus tshawytscha) populations that were introduced to New Zealand in the early 1900s using a common garden approach. They report consistent evidence for heritable differences among populations in both size and age at maturity, with the patterns often corresponding to those observed in the wild.

The second study to exploit introduced populations, and thus provide an insight into the rate at which adaptation can occur, is that of Junge et al. (2011). They assess the temporal stability of population genetic structure at a microgeographic scale in a European grayling (Thymallus thymallus) lake system in Norway. Populations in this system have recently been shown to have evolved adaptations to tributary-specific thermal regimes in just 22 generations since colonisation (Kavanagh et al., 2010). Although population structuring was generally weak, it was mostly stable, but there were exceptions with high levels of migration often observed. Thus, they suggest that habitat-specific adaptation in this system has preceded the development of consistent 
population substructuring and in the face of high levels of gene flow.

Kapralova et al. (2011) are also interested in understanding the relative roles of migration and natural selection in maintaining phenotypic diversity, but at broader geographic and temporal scales in naturally occurring populations. They evaluate the potential roles of genetic connectivity and natural selection in the maintenance of adaptive phenotypic differences among morphs of Arctic charr, Salvelinus alpinus, in Iceland at two different geographical scales. At the broad geographic scale, they report evidence suggesting that the small benthic morph has had the opportunity to evolve multiple times. Within a single lake (Lake Thingvallavatn), they observe modest genetic differentiation between two morphs, but this level of differentiation is nonetheless consistent with strong reproductive isolation throughout the Holocene.

The final two studies make use of the increasing genomic resources that have become available for salmonid species over the past few years and utilise genomescan approaches to identify loci potentially affected by selection and combine this with assessments of the potential influence of hatchery-stocked or aquacultureescaped individuals. Meier et al. (2011) compare the number of 'outlier loci' at different geographic scales and find a significantly higher number of outlier loci between regions compared with within regions. In addition, they discover that the number of outliers observed increases with increasing geographical distance. This indicates that the prevalence of local adaptations increases with increasing geographical distance and is in accordance with the review by Fraser et al. (2011). Finally, Bourret et al. (2011) use single-nucleotide polymorphisms (SNPs) and microsatellites to assess temporal changes in the genetic make-up of a threatened Atlantic salmon (Salmo salar) population in Canada. An SNP genome scan identified a temporal decrease in the number of candidate loci potentially under directional selection, and they suggest that introgression with farmed fish may thus be resulting in significant alteration of the genetic integrity of the native population, including possible loss of adaptation to wild conditions.

So what can we conclude about the genetics of local adaptation in salmonid fishes? First, the review articles provide strong evidence that local adaptations are indeed common in salmonid fishes. Fraser et al. (2011) and also Meier et al. (2011) add a geographic scale to this conclusion: the further apart two populations are, the more likely they are to have evolved adaptations to their specific local conditions. However, the studies in this special issue also provide guidelines for future research. In particular, it is clear that still very little is known about the genetic basis of the observed local adaptations. As noted in several of the papers, there is great hope that recent developments in genomic methodologies will pave the way for more comprehensive studies of the genetic basis of local adaptation. As noted by Fraser et al. (2011), integrative approaches will be required in order to establish causal links between the molecular and phenotypic levels, and this can best be achieved through increased interdisciplinary collaboration. Of particular significance for salmonid fish genetics research is the imminent completion of the Atlantic salmon genome sequence (Davidson et al., 2010). As such, this special issue can be seen as bringing to a close the study of the genetics of salmonid local adaptation in the pre-genome era and we all await with anticipation the opening of the post-genome chapter.

\section{Conflict of interest}

The author declares no conflict of interest.

\author{
CR Primmer \\ Department of Biology, University of Turku, Turku, Finland \\ E-mail: craig.primmer@utu.fi
}

\section{References}

Adkison M (1995). Population differentiation in Pacific salmon: local adaptation, genetic drift or the environment? Can J Fish Aquat Sci 52: 2762-2777.

Bourret V, O'Reilly PT, Carr JW, Berg PR, Bernatchez L (2011). Temporal change in genetic integrity suggests loss of local adaptation in a wild Atlantic salmon (Salmo salar) population following introgression by farmed escapees. Heredity 106: 500-510.

Carlson SM, Quinn TP, Hendry AP (2011). Eco-evolutionary dynamics in Pacific salmon. Heredity 106: 438-447.

Davidson WS, Koop BF, Jones SJM, Iturra P, Vidal R, Maass A et al. (2010). Sequencing the genome of the Atlantic salmon (Salmo salar). Genome Biol 11: 403.

Fraser DJ, Weir LK, Bernatchez L, Hansen MM, Taylor EB (2011). Extent and scale of local adaptation in salmonid fishes: review and meta-analysis. Heredity 106: 404-420.

Garcia de Leaniz C, Fleming IA, Einum S, Verspoor E, Jordan WC, Consuegra $S$ et al. (2007). A critical review of adaptive genetic variation in Atlantic salmon: implications for conservation. Biol Rev Camb Philos Soc 82: 173-211.

Hutchings JA (2011). Old wine in new bottles: reaction norms in salmonid fishes. Heredity 106: 421-437.

Jensen LF, Hansen MM, Pertoldi C, Holdensgaard G, Mensberg KLD, Loeschcke V (2008). Local adaptation in brown trout early life-history traits: implications for climate change adaptability. Proc $R$ Soc B 275: 2859-2868.

Junge C, Vøllestad LA, Barson NJ, Haugen TO, Otero J, Sætre G-P et al (2011). Strong gene flow and lack of stable population structure in the face of rapid adaptation to local temperature in a spring-spawning salmonid, the European grayling (Thymallus thymallus). Heredity 106: 460-471.

Kapralova KH, Morrissey MB, Kristjánsson BK, Ólafsdóttir GÁ, Snorrason SS, Ferguson MM (2011). Evolution of adaptive diversity and genetic connectivity in Arctic charr (Salvelinus alpinus) in Iceland. Heredity 106: 472-487.

Kavanagh KD, Haugen TO, Gregersen F, Jernvall J, Vollestad AL (2010). Contemporary temperature-driven divergence in a Nordic freshwater fish under conditions commonly thought to hinder adaptation. BMC Evol Biol 10: 350.

Kawecki TJ, Ebert D (2004). Conceptual issues in local adaptation. Ecol Lett 7: 1225-1241.

Kinnison MT, Quinn TP, Unwin MJ (2011). Correlated contemporary evolution of life history traits in New Zealand Chinook salmon, Oncorhynchus tshawytscha. Heredity 106: 448-459.

McGinnity P, Jennings E, DeEyto E, Allott N, Samuelsson P, Rogan G et al. (2009). Impact of naturally spawning captivebred Atlantic salmon on wild populations: depressed recruitment and increased risk of climate-mediated extinction. Proc $R$ Soc B 276: 3601-3610.

Meier K, Hansen MM, Bekkevold D, Skaala Ø, Mensberg K-LD (2011). An assessment of the spatial scale of local adaptation in brown trout (Salmo trutta L.): footprints of selection at microsatellite DNA loci. Heredity 106: 488-499. 
Nielsen EE, Hansen MM (2008). Waking the dead: the value of population genetic analyses of historical samples. Fish Fisheries 9: 450-461.

Stearns SC, Hendry AA (2004). The salmonid contribution to key issues in evolution. In: Hendry AA, Stearns SC (eds).
Evolution Illuminated: Salmon and their Relatives. Oxford University Press: Oxford. pp 3-19.

Taylor EB (1991). A review of local adaptation in Salmonidae, with particular reference to Pacific and Atlantic salmon. Aquaculture 98: 185-207. 